\title{
Monitoring of renal transplants with ultrasound
}

\author{
M L Nicholson, Anne Bell, S D Parvin, \\ Annabel M Madden, P K Donnelly, \\ P S Veitch, P R F Bell
}

University Department of Surgery, General Hospital, Leicester LE5 4PW

$M$ L Nicholson, FRCS, transplant fellow

Anne Bell, SRN, transplant ultrasonographer

S D Parvin, FRCS, lecturer Annabel M Madden, MB, transplant senior house office

P K Donnelly, FRCS, senior lecturer

P S Veitch, FRCS, consultan P R F Bell, FRCs, professor

Correspondence to: $\mathrm{Mr}$ Nicholson.

Br.Med f 1989:298:296
During acute rejection a transplanted kidney swells, and so a subjective evaluation of the the size of the graft by palpation is generally used to diagnose rejection. Ultrasound scanning, however, provides a more accurate assessment of renal size.

\section{Patients, methods, and results}

Episodes of acute graft dysfunction (increase in creatinine concentrations of $\geqslant 30 \mu \mathrm{mol} / \mathrm{l}$ between two successive measurements) occurring during January 1984 to February 1988 were studied retrospectively. Only patients who underwent a Tru-Cut biopsy of their transplant were included so that histological evidence was available. Patients with a proved urinary tract infection or evidence of ureteric obstruction were excluded. With these criteria we identified 131 episodes of acute graft dysfunction in 80 patients.

The transplanted kidney was scanned daily from the first postoperative day until the patient was discharged. Subsequent scanning was performed in the transplant clinic at varying intervals. All scans were performed by the same ultrasonographer $(\mathrm{AB})$ with an Aloka SSD630 real time ultrasound machine fitted with a $3.5 \mathrm{MHz}$ transducer. The ultrasound probe was lined up over the hilum to show a transverse cross section. The outline of the kidney was traced, and from this the machine calculated and displayed the area of the cross section $\left(\mathrm{cm}^{2}\right)$. Four measurements were made each

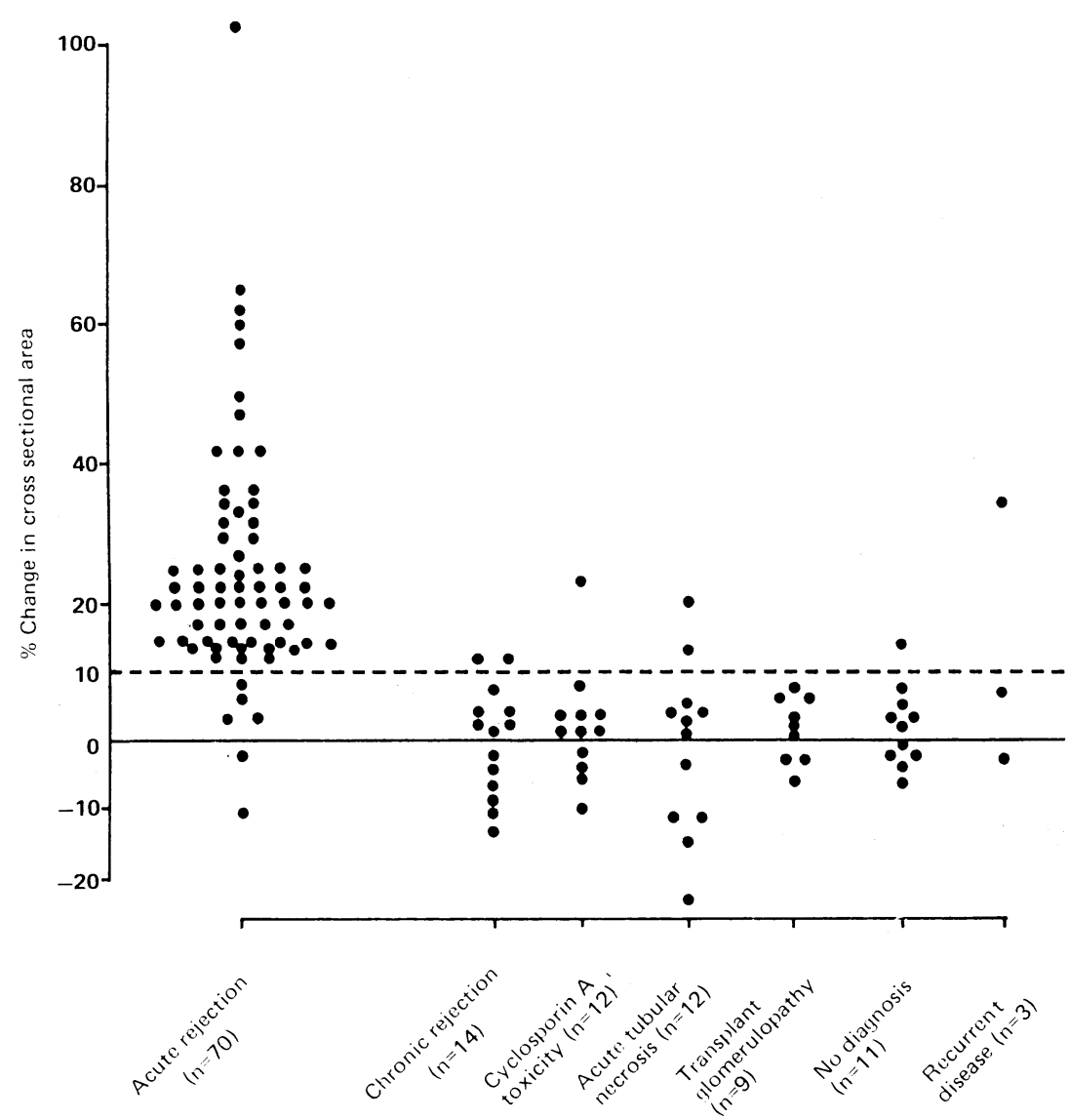

Changes in cross sectional area of transplant in 131 cases of acute graft dysfunction. Dotted line shows 10\% diagnostic level, which suggests acute rejection day, and these values and their means were recorded.

Anatomical reference points (for example, vessels emerging from the hilum) and a picture of the reference section were used to identify the same section each time. Biopsies were peformed with a Tru-Cut needle under ultrasound control. Cyclosporin A toxicity was diagnosed by a rise in serum creatinine concentration of $\geqslant 30 \mu \mathrm{mol} / \mathrm{l}$ between two consecutive measurements followed by a return to the baseline concentration after a $30 \%$ reduction in dose; by blood cyclosporin concentrations of over $600 \mu \mathrm{g} / \mathrm{l}$; and by an absence of an acute cell infiltrate in the biopsy specimen.

The reproducibility of scanning was assessed by repeated measurement of the same scan; calculating the variation among the four scans produced each day; and calculating the day to day variation in measurements of an 18 month old transplant with stable function. In each case the variation was always less than $6 \%$. We therefore arbitrarily defined an increase in cross sectional area of $10 \%$ or more as important. A scan showing such an increase was referred to as a positive scan, which suggested an episode of acute rejection.

The figure shows the changes in cross sectional area for the 131 episodes of acute graft dysfunction. There were 70 cases of acute cellular rejection, and in 64 of these the ultrasound scan was positive (range in increase in size $10-103 \%)$. In six cases the scan was falsely negative (sensitivity $91 \%$ ). The figure shows the other diagnoses: in this group there were 54 true negative and seven false positive scans (specificity $89 \%)$. The predictive value of scanning was high (90\%) for both positive and negative scans.

\section{Comment}

Despite recent advances in immunosuppression rejection remains the central problem in renal transplantation, and there has been considerable interest in developing techniques of early diagnosis. Tru-Cut biopsy, ${ }^{2}$ fine needle aspiration biopsy, ${ }^{3}$ and intrarenal manometry ${ }^{+}$have all been used with success but are invasive. Technological developments have made possible accurate measurements of the size of renal transplants with ultrasound, which provides a more objective assessment than palpation. We have shown that ultrasound measurement of the cross sectional area of a transplant is sensitive and specific in differentiating acute rejection episodes from other causes of deterioration in allograft function. The method is quick, reproducible, and non-invasive and worthy of more widespread use. Continuous wave Doppler ultrasound has been used recently to diagnose cyclosporin toxicity by measuring the associated decrease in graft perfusion. ${ }^{5}$ Using combined conventional and Doppler ultrasound in assessing graft dysfunction has potential for further study.

We thank Dr Yvonne Rees, who helped to develop the ultrasound technique in its early stages, and $\mathrm{Dr} \mathrm{H}$ Mackay and $\mathrm{Dr} \mathrm{K}$ O'Reilly for interpreting the transplant biopsy material.

1 Parvin SD, Rees Y, Veitch PS, Bell PRF. Objective measurement by ultrasound to distinguish cyclosporin A toxicity from rejection. $B r \mathcal{F}$ Surg ultrasound to dis
1986;73:1009-11.

2 Klintmalam G, Bergstrand A, Ringden O, et al. Graft biopsy for the differentiation between nephrotoxicity and rejection in cyclosporin $A$ treated renal transplant recipients. Transplant Proc 1983;15:493-6.

Hayry $\mathrm{P}$, Von Willebrand E. Monitoring human renal allograft rejection with fine needle aspiration cytology. Scand I Immunol 1981;13:87-97.

4 Salaman JR, Griffin PJA. Fine needle intrarenal manometry. A new test for rejection in cyclosporin A treated recipients of renal transplants. Lancel 1983;ii:709-11.

5 Ubhi CS, Irving HC, Norwood HM, Guillou PJ, Gile GR. Monitoring of rena allografts by Doppler ultrasound. Ann R Coll Surg Engl 1987;69:229-32.

(Accepted 14 November 1988 